\title{
Sexual Behavior, HIV/AIDS Epidemic and Sustainable Development in Nigeria: A Gender Perspective
}

\author{
John Lekan Oyefara PhD \\ Department of Sociology, University of Lagos, Akoka, Yaba, Lagos, Nigeria \\ Email: oyefara@yahoo.com / loyefara@unilag.edu.ng
}

Accepted: Feb 17, 2013 Published: March 16, 2013

Doi:10.5296/jsr.v4i1.3386

URL: http://dx.doi.org/10.5296/jsr.v4i1.3386

\begin{abstract}
Nigeria is the most populous country in Africa. With an estimated population size of over 160 million and HIV prevalence rate of 4.6 percent in 2008, over 5 million Nigerians are currently living with HIV. Using data from Nigeria's national surveys such as Nigeria Demographic and Health Survey (2008), Antenatal Sentinel Surveys (1991-2008), National HIV/AIDS and Reproductive surveys (2003-2007), HIV/AIDS Behavioural Surveillance Survey (2000) and HIV/STI Integrated Biological Behavioural Surveillance Survey (2008) this paper examines the driving forces of HIV transmission in Nigeria. Findings of the study revealed that men are more likely than women to have multiple sexual partners, practice unprotected sex and engage in transactional sex. In conclusion, it has been recommended that efforts need to be put together to strengthen Nigerian women economically and socially in order to reduce their level of vulnerability an susceptibility to HIV infection and there is a need to strengthen the national HIV/AIDS response mechanisms, most especially at local government level to include improvement of women economic power, promotion of women's reproductive health rights and self esteem, prevention of mother to child transmission and total eradication of obnoxious cultural practices that made women to be at high risk of the virus.
\end{abstract}

Keywords: HIV/AIDS, Sexual Behaviour, Gender, Development, Nigeria.

\section{Introduction}

The HIV/AIDS pandemic constitutes one of the greatest health and developmental challenges of our time. The result of the 2008 HIV sentinel surveillance using pregnant women attending antenatal clinics has further confirmed the magnitude of the problem in Nigeria. The epidemic has affected all the geopolitical zones, states and locations of the country with wide disparities. The National HIV prevalence among women attending antenatal clinics in Nigeria in 2008 was found to be $4.6 \%$. The prevalence ranged from $1.0 \%$ in Ekiti State to $10.6 \%$ in Benue State. All the States of the Federation and FCT were affected by the epidemic with none recording less than $1.0 \%$ prevalence (FMH, 2008). The first cases of HIV/AIDS were 
diagnosed among some homosexual in 1981 at the United States of America (FMHSS, 1992; Daini, 2002). Barely 30 years after, the disease has permeated the nine continents of the world with over 60 million people being infected with HIV infection (Kiragu, 2001). The hyper-geometric rate of spread and transmission of HIV/AIDS pandemic raises some fundamental questions about the nature and major route of contracting HIV/AIDS infection/disease in general form. The questions are: What is the major route of contracting HIV infection that makes every human being in the world vulnerable to the disease? Are there socio-cultural, economic and demographic factors that make some set of people in a particular region, section and community more susceptible to the pandemic? Is Sociological enterprise useful in identifying these factors? and finally, what can be done to stem the spread of the HIV/AIDS pandemic among every human race, especially in Nigeria? Are there any gender dimensions to the spread and effects of the pandemic? The next sections of this article will provide answers to these questions.

\section{National Response to HIV/AIDS in Nigeria: Structure and Effectiveness}

A national health sector-based response was established in 1986 following the emergence of the epidemic in the country with Federal, State and LGA structures to drive it. In 2000, an expanded national multi-sectoral response was put in place with the establishment of a Presidential Council on AIDS (PCA) and National Action Committee on AIDS (NACA) to drive the response. State Action Committees on AIDS (SACAs) and Local Government Action Committees on AIDS (LACAs) also came into operation. Prevention, treatment, care and support interventions have continued to expand impressively since then, guided by appropriate policies (e.g. National HIV/AIDS Policy), strategic plans (e.g. HIV and AIDS Emergency Action Plan-HEAP and National Strategic Framework-NSF) and guidelines (e.g. ART, PMTCT, and HCT). HIV Counselling and Testing and ART care are currently the most rapidly expanding interventions. The multi-sectoral response has resulted in better resource mobilization and coordination of the many stakeholders (Public, Private and the civil societies) applying the principle of "Three Ones" (One national structure, one strategic plan and one monitoring and evaluation framework). Participation of the private sector, civil societies, bilateral (USG/PEPFAR, DFID) and multi-national organizations, PLWAs and United Nation Agencies has continued to improve over the years. More resources have also been accessed from governments, private enterprises and Global Fund to fight HIV/AIDS, Tuberculosis and Malaria (GFATM)) (FMH, 2008).

It is imperative to note that the above stated national response to the pandemic is characterized by seemly structural defectiveness in terms of coordination and implementation of programmes. In addition, the activities of various State actors in the areas of HIV/AIDS have been significantly influenced by political climate. A critical evaluation of the political environment in the country reveals inconsistency in the level of political office holders across the three tiers of government (i.e. federal, state and local government level) in the country. Existing data in the country are characterised by issues such as out-of-stock of Anti-retroviral therapy, poor coordination of non-state actors and civil society activities working on the 
HIV/AIDS and cancerous and endemic corruption that has permeated the various sectors of the country. Consequently, the prevalence rates of HIV virus are fluctuating at the national level and disproportionately higher in some States and Local Government Areas of the country. In order to achieve success in the battle against the pandemic, the Nigeria national response needs to be strengthened most especially in the areas of project development, implementation, evaluation and coordination.

\section{Routes of HIV Transmission and Sexuality}

HIV is not a communicable or contagious infection therefore it cannot be contracted through casual contacts. Specifically, HIV can be contracted when blood or semen (male seminal fluid) of an infected person comes in contact with the blood, or mucus membrane (inner lining of the vagina, anus etc) of a healthy person. According to ICW (1999), this can happen in the following circumstances: having unprotected (without a condom) vaginal or anal sex with someone who is HIV positive (i.e. heterosexual and homosexual contacts); sharing syringes, infected equipment and any skin-piercing instruments such as needles, razor blades, etc which have not been properly cleaned or sterilized; being given untested blood transfusions or blood products which are infected with HIV; from infected mother to her infant during pregnancy, childbirth or through the breast milk. Also, HIV infection can be contracted through what is known as "Deep kissing", "French kissing" or "Wet kissing".

Deep/French/Wet kissing is a type of kissing in which a sexual partner's tongue is put into the partner's mouth and it is usually accompanied by greater feelings of excitement and desire to explore other areas of the body (Tabifor, 2002). HIV may be transmitted through Deep/French/Wet kissing because, copious amount of saliva is exchanged during this process, and it has been proved that saliva contains certain level of HIV virus. Thus the presence of sores (injuries) in the mouth increases the risk of transmission of HIV during Deep/French/wet kissing. Results of studies from different parts of the world reveal that sexual intercourse is the major route of HIV transmission globally (UNAIDS/WHO, 1998). In Nigeria, heterosexual contact is the major route of HIV transmission in the country (FMHSS, 1992). In view of the importance of sexual intercourse in the contraction and transmission of HIV infection globally and more especially in sub-Saharan Africa, the home of 70 percent of the people who are infected with HIV (UNAIDS, 1998), it is imperative and necessary to examine in detail, the different types of sexual intercourse that exist in the contemporary time and the degree or possibility of contracting HIV infection in each of these types of sexual intercourse. Basically, in the present modern days, there are three major types of sexual intercourse. These are: a.) Anal Sex: This is when a man puts his penis into the anus of a woman or another man with the aim of having sexual relation. Biological studies have showed that the walls of anus are thinner than the vaginal lining and, therefore, can easily be broken during intercourse (Tabifor, 2002). This will invariably facilitate exchange of fluids (semen and blood), hence HIV contraction and transmission is very high during anal sex. b.) Oral Sex: This occurs when a woman sucks or licks a man's penis (fellatio); or when a man licks a woman's vaginal area (cunnilingus) (Tabifor, 2002); or when a man or 
woman licks another man's or woman's anus - a practice sometimes called "rimming" (Johnson, 1992). Sexual fluids (seminal and vaginal) in the mouth can pose a threat in HIV transmission. Very tiny cracks in the mouth, especially within the gums, can serve as a route for HIV transmission during oral sex. c.) Carnal Sex: This is a situation whereby a man put his penis into the vagina of a woman in order to have sexual relation. This is the normal, natural, traditional and popular heterosexual intercourse. It is the major route of HIV transmission in Nigeria (FMHSS, 1992).

The above three types of sexual intercourse can also be sub-divided into two main categories on the basis of nature of the partners. These are: heterosexuality and homosexuality. a.) Heterosexuality: This is a type of sexual intercourse which involves two people of opposite sex i.e. male and female. Indiscriminate and unprotected heterosexual sex puts the people involved in the risk of HIV contraction. b.) Homosexuality: It is a practice among individuals with strong sexual attraction to members of the same sex. Homosexuality is commonly used to describe men who are sexually attracted to other men, while lesbianism refers to women who are sexually attracted to other women. But from the definition given above, lesbianism is a form of homosexuality. Thus homosexual males are called gays or gay males, while homosexual females are called lesbians. Therefore, Tabifor (2002) give the two types of homosexuals as follows: i.) Gay Males: These are males who are erotically attracted to and desire to form romantic relationship with other males. Gay males tend to engage in sexual activities such as kissing, hugging, petting, manual masturbation, oral and anal intercourse. HIV can be easily transmitted through most of these methods. ii.) Lesbians: These are females who are erotically attracted to and desire to form romantic relationship with other females. Lesbians' partners practice kissing, manual and oral breast stimulation, manual and oral genital stimulation and genital apposition. It should be noted that lesbians are also at greater risk of contracting HIV infection like gay males. This is because, some lesbians are commercial sex workers, some of them use injectable drugs, some could be raped, some seek donor insemination in order to become pregnant, some of them also use risky practices like sharing of sex toys with other women partners or penetrating each others vagina or anus manually with fingers that have cuts or bleeding hand nails (Tabifor, 2002). These practices present a great risk of contracting HIV infection among lesbian partners.

\section{Theoretical underpinning}

The theoretical orientation that gives a very clear insight into gender dynamics of HIV/AIDS in Nigeria is the theory of Cultural Determinism. Cultural Determinists argue that physiological differences in men and women merely signal differentiation in gender roles. They do not cause them. Differentials in experiences of men and women are not universal. They are determined by cultures (Basow, 1992). The kernel of the Cultural Determinists' theoretical position on HIV prevalence is that the differences in the prevalence of HIV, and its variations across cultural boundaries are culturally determined. It goes without saying that patriarchy, an enduring system of inequality, which characterizes the Nigerian society, lies at the very heart of all practices which made women to be highly vulnerable and susceptible to 
HIV.

The theory gives provide explanation on how men play an important role as head of households, the ones who make the majority decisions pertaining to family life and the society in general. Traditionally, wives address their husbands as lord or master or some other appellation that underscores their exalted position. Men make sexual demands and their wives oblige. All these are determined, not by biological differences, but by a culture that is characteristically patriarchal. The view is shared by Radical Feminists (Ritzer, 2000).

\section{Methodology}

The methodological approach of the study is an eclectic framework of data collection which involves a triangulation of archival materials at national level and in-depth interview research method. The archival materials adopted include: Nigeria Demographic and Health Survey (2008), Antenatal Sentinel Surveys (1991-2008), National HIV/AIDS and Reproductive surveys (2003-2007), HIV/AIDS Behavioural Surveillance Survey (2000) and HIV/STI Integrated Biological Behavioural Surveillance Survey (2008). These sources provide secondary data. The primary data were generated with the aids of in-depth interview research method. The respondents for in-depth interview were the stakeholders in the planning, management, and implementation of HIV/AIDS projects (HIV/AIDS Project Managers-State and Non-State actors) in Nigeria including People Living with HIV/AIDS and community leaders. These categories of people were selected because of their relevance to the study. In all, a total of twenty (20) in-depth interviews were conducted. A purposive sampling method was used to select the respondents. The in-depth interview study was conducted between August and September, 2012. The analytical method adopted in the study was purely narrative and descriptive in nature.

\section{Findings:}

\section{HIV/AIDS Epidemiology in Nigeria}

In Nigeria, the first case of AIDS involving a sexually active 13 years old girl was officially reported in 1984 (FMHSS, 1992). Since then, the number of people infected with HIV and those who have developed AIDS and died of the pandemic has been increasing progressively until the year 2001. Specifically, the national median HIV prevalence increased from 1.8 percent in the year 1991 to 5.8 percent in the year 2001. As a result of political commitment at the highest level (from 1999) which put the right structures in place, provided funding and enabling environment for development partners, local and international NGOs, FBOs and CSOs, the prevalence rates declined consistently from 5.8 percent in 2001 to 4.4 percent in the year 2005 but increased slightly to 4.6 percent in the year 2008 (FMH, 2008). The trends of HIV prevalence in Nigeria can be seen in graph form in Figure 1. One of the State actors in HIV/AIDS in Lagos State explicates the nature of development in the transmission trends and management of HIV/AIDS in Nigeria in the following way during in-depth interview: 
During the military era, Nigeria government lack political will and efficient structure to address the problem of HIV/AIDS. But with the advent of democracy in 1999, the National Action Committee on HIV/AIDS was strengthened which gradually metamorphosed to a well rooted Federal government Agency with mandates to develop, execute and evaluate different pragmatic intervention programmes to fight HIV/AIDS. Since then Nigeria has been able to record significant reduction of the pandemic

Another community leader in the country stated that:

The awareness of HIV most especially about its modes of transmission and its incurable nature is highly prevalent in the country in the recent years. Presently there is HIV/AIDS education through different communication channels and in different institution including primary schools. If these efforts can be sustained, the fight against HIVIAIDS will be ultimately successful in the country.

These responses suggest that recent governments in the country have be concerned and put resources together to mitigate the impact of the pandemic.

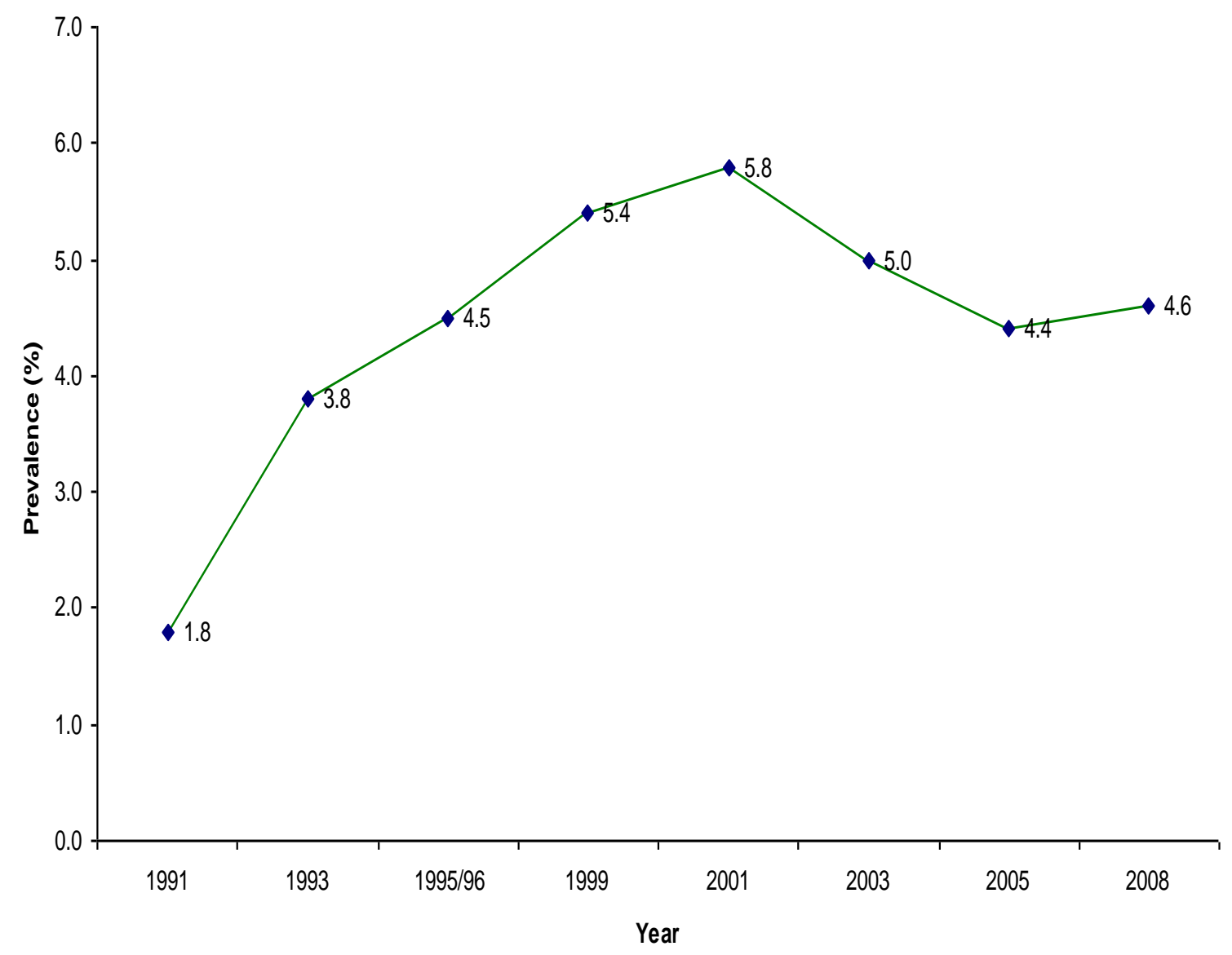




\section{Macrothink}

Figure 1: HIV prevalence rates in Nigeria (1991-2008)

Source: Federal Ministry of Health, 2008.

Data from other independent sources in the literature also corroborate the initial rapid increase and recent slight decline of HIV/AIDS pandemic in Nigeria. The existing information shows that every individual, within the country is vulnerable to HIV infection since the few data from the national HIV sentinel surveys indicated a rapid transition from the near zero prevalence in 1990 to a 5.4 percent prevalence rate amongst the adult population by 1999 (FMH, 1999). In the year 2002, national estimates show that 3.47 million Nigerians are HIV positive, the infection decreased life expectancy in the country in the year 2002 by 4.5 years, cumulative number of deaths due to AIDS as 1.4 million, and number of AIDS orphan as 847 thousand in the year 2002 alone (NACP/NAC/FUTURE/USAIDS, 2002). These pieces of data suggest the need to sustain various existing solutions to the problems of HIV/AIDS pandemic in Nigeria.

\section{Rural-Urban and Sex Distribution HIV in Nigeria}

HIV/AIDS prevalence is disproportionately prevalent in rural and urban areas in Nigeria and it is favour of urban areas. The 2008 survey has further confirmed higher urban prevalence to rural, while there is higher prevalence among women than men in general (FMH, 2008). Estimates from the 2005 ANC survey for instance showed that 2.86 million persons were living with HIV in Nigeria. The survey showed highest HIV prevalence among women aged 25-29 years (4.9\%) followed closely by those aged 20-24 years (4.7\%). Also, the survey showed highest prevalence among women with only secondary level education (5.0\%) (FMH, 2005). In 2007, the national population based survey showed an overall HIV prevalence of $3.6 \%$, (4.0\% among females and 3.2\% males) (FMH, 2008). One of the in-depth interview respondents who was an executive officer of Non-Governmental Organization has this to say about the distribution of HIV/AIDS in the country:

The available data in Nigeria reveal high prevalence of HIV/AIDS among urban dwellers and females compare to rural dwellers and males. These are the distribution pattern we have seen in both national, regional and community based studies. The high vulnerability of urban dwellers and women has also informed the location most of our intervention programmes. This is not to say that rural dwellers and men are not susceptible to the virus, in fact current data also suggest that we should not ignore neither rural dwellers nor men in our prevention programmes. The available data show that they are also vulnerable.

This appears to suggest that in Nigeria HIV infection was initially more concentrated in the urban areas but as the prevalence increases, rural areas and dwellers become susceptible and invariably affected. It is imperative to note that because rural dwellers were disadvantaged in terms of HIV awareness, knowledge and services, the epidemic gained ground relatively quicker and has been spreading relatively faster subsequently in the rural areas in the country. 


\section{Risky Sexual behavior in Nigeria}

Sexual behaviour refers to the manner in which human beings experience and express their sexuality. It encompasses a wide range of activities, such as strategies to find or attract partners (mating and display behaviour), interactions between individuals, physical or emotional intimacy, and sexual contact. The term sexual behaviour can also refer both to acts involving two or more people, as in sexual intercourse, oral sex, or mutual masturbation, and to the one person activity of masturbation. In some cultures, sexual activity is considered acceptable only within marriage, although premarital and extramarital sex is universal. Some sexual activities are illegal either universally or in some countries, and some are considered to be against the norms of a society. For example, sexual activity with a minor and sexual assault in general are criminal offenses in many jurisdictions (Ames, 1990). Human sexuality has intricate meaning for both individuals and societies. It is a complex mixture of biological response, psychological meaning and societal/cultural overlays. It is only in recent years that sexuality has been studied in a scientific way by Sociologists who seek to report and analyze current sexual behaviour.

The national HIV/AIDS and reproductive health survey (NARHS) 2007 like other previous national surveys revealed that men play significant role in the rapid transmission of HIV in Nigeria since they are more likely to engage in risky sexual behaviors more than women. In general, $83 \%$ of female respondents and $73 \%$ of male respondents have had sexual intercourse. Specific analysis of the study showed that in overall about $9 \%$ of females and $20 \%$ of males reported that they had sex with non-marital partners in the last 12 months preceding the survey. In addition, $5 \%$ of females and $8 \%$ of males reported that they have ever accepted or given gifts of some kind or favour in exchange for sex. The proportion of respondents who had received or given some kind of gifts or favour for sex was higher among the younger age group (15-29 years), in the urban areas and among those with primary, secondary and higher education. With reference to multiple sexual partners, of all the respondents who had ever had sex within the period, only $3 \%$ of females compared with $27 \%$ of males reported having multiple sexual partners. Further analysis of these data showed that $1 \%$ of females who had sex in the 12 months preceding the survey had multiple non-marital sexual partners compared with $7 \%$ of males. A response during in-depth interview with a community leader show how men have been significant agents of HIV transmission in the country:

In order to have a clear picture of the dynamics of sexual networking and behavior in Nigeria, someone needs to have basic knowledge of the contextual factors of the country. For example, Nigeria is multi-ethnic society with over four hundred ethnic groups. Coupled with the patriarchal nature of Nigeria society, most of these ethnic nationalities have different culturally construct notions about sexual intercourse some of which are inimical to their men and women. Polygyny for instance is highly prevalent across all the ethnic groups. This is a belief and practice that makes man to be a husband of many wives at the same time, but a 
woman cannot be a wife to more than a man at a time. In addition, men were socialized to initial sex. These among other cultural practices make men to engage in risky sexual behavior compare with women.

Another most common non-marital type of non-marital, non co-habiting sexual relationship in Nigeria is the boyfriend/girlfriend relationship. About $9 \%$ of female respondents compared with $19 \%$ of males in this survey had sex with boyfriends and girlfriends respectively during the last 12 months preceding the survey. It is imperative to note that abstinence, mutual fidelity; condom use, and reduction in the number of sexual partner are key strategies aimed at preventing HIV transmission in the country. Among sexually active respondents, about $8 \%$ of females and $24 \%$ of males were current condom users. (FMH, 2008).

\section{Sexual Behaviour and HIV Prevalence among Most at Risk Populations (MARPS)}

The 2007 Integrated Biological and Behavioural Surveillance Survey (IBBSS) focussed on potential sources and modes of new HIV transmission among groups that are at higher risk of HIV in Nigeria. MARPS are the high-risk groups that are highly susceptible and vulnerable to both sexuality transmitted infections (STIs) and HIV in Nigeria. In the 2007 IBBSS these groups include both brothel-and non-brothel-based female sex workers (FSW), men who have sex with men (MSM), injecting drug users (IDU), transport workers (TW) and men and women in the uniformed services (armed forces and the police). With over $30 \%$ of all FSW infected with HIV, the 2007 IBBSS has identified FSW as the sub-population most affected by HIV/AIDS in Nigeria. Thus, female sex workers constitute an important reservoir of HIV infection for continuous transmission to the general population. HIV prevalence among this group has remained high and on the increase from 17.5\% (among the brothel based FSW) in 1991 to $22.5 \%$ in 1993 and to $37.4 \%$ in 2007 (IBBSS, 2007).

Table 1: HIV Prevalence rates among Most at risk populations-IBBSS, 2007

\begin{tabular}{|l|l|l|}
\hline S/N & MARPs & HIV Prevalence rate (\%) \\
\hline 1 & Brothel Based Female Sex Workers & 37.4 \\
\hline 2 & Non-Brothel Based Female Sex Workers & 30.2 \\
\hline 3 & Men who have sex with men (MSM) & 13.5 \\
\hline 4 & Armed Forces & 3.1 \\
\hline 5 & Police & 3.5 \\
\hline 6 & Transport workers (TW) & 3.7 \\
\hline 7 & Injecting Drug Users (IDU) & 5.6 \\
\hline
\end{tabular}

After FSW, MSM recorded the next highest HIV prevalence with 13.5\%. Most MSM sexual partnerships with other men in the past six months were non-paying, though up to $50 \%$ of them also had sex with women and around one third had also sold sex to other men. A smaller proportion had purchased sex from other men, and less than $10 \%$ had sex with FSW. The IDU group had the third highest HIV prevalence (5.6\%) after FSW and MSM among groups 
surveyed. The lowest HIV prevalence in this survey was found in the three predominantly male occupational groups, with all three groups in the range of $3.1-3.7 \%$. With the police sample composed of $25 \%$ females, a sub analysis was conducted on HIV prevalence among female and male police. In all cases, HIV prevalence among female police was higher than among males, particularly in FCT where $12.7 \%$ of female police were HIV positive as against $5.6 \%$ of males. Multiple partnerships are quite common among the armed forces, police and TW. $37.3 \%$ of armed forces, $29.4 \%$ of police and $37.9 \%$ of TW reported sex with more than one partner in the previous 12 months. After regular partners, girlfriends were the next most common type of sexual partner reported. Condom use at last sex with girlfriends was higher among the armed forces (64.7\%) than the police and TW (45.4\% and 45\% respectively). This fact combined with higher reported condom use with commercial partners likely contributed to the armed forces returning the lowest HIV prevalence among the three groups (IBBSS, 2007).

\section{Sexual behavior and HIV prevalence in Nigeria: Gender analysis}

It is imperative to note that there exist compelling sociological and institutional factors that are favouring African men in matters affecting marital and family life as previously argued above. In the continent which is highly patriarchal in nature, men play an important role as head of households, the ones who make the majority decisions pertaining to family life and the society in general. Traditionally, wives address their husbands as lord or master or some other appellation that underscores their exalted position. Men make sexual demands and their wives oblige. Furthermore, based on the theory of cultural determinism, men, just like women, are also a sub-culture in any society. Men take up specific professions, sports, and activities known to be "male" oriented and that tend to change and evolve over time. Men are sexual partners-that is, they play a role in sexual initiation, establishing sexual unions, or in stopping them. Men are husbands and fathers, and as such they are central figures in marriage and reproduction.

Although Nigerian males are more likely to engage in multiple sexual relation compared to females according to various data from national surveys, but they are more likely to use condom than females. Consequently, the prevalence rate of HIV among females is higher than the one among Nigerian males. Gender analysis revealed behind this disproportionate HIV prevalence among both males and females in the country. Women especially young ones are more susceptible to HIV infection. Other associated factors to patriarchy are so many cultural practices that make women to be more vulnerable to HIV contraction. These cultural practices include: sexual abstinence during breastfeeding, polygyny, divorce and female genital mutilation. Apart from these cultural/traditional practices, evidence from biological research also indicates the high susceptibility of women to HIV contraction. For example, it has been established that the risk of becoming infected with HIV during unprotected sex is two to four times greater for a woman than for a man (Ainsworth and Over, 1997; UNAIDS, 1999; Royce et al. 1997). Male-to-female transmission is more likely because during vaginal intercourse a woman has a larger surface area of her genital tract exposed to her partner's 
sexual secretions than does a man. Also, HIV concentration is generally higher in a man's semen than in a woman's sexual secretions (Laurence, 1999; Watstein and Laurich, 1991). Thus, the cultural power of men of domination in patriarchy makes their biological vulnerability to be the domain where HIV travails. Basically, sexuality refers to erotic stimulation. Erotic stimulation refers to what a particular society teaches are the pathways, directly or indirectly, to genital response. The learned aspect of erotic stimulation is obvious. For instance, in many male dominated cultures, it is believe that for a male to reach orgasm quickly, in a matter of seconds, is something to be proud of. On the other hand, western society today, contend that such a male is a premature ejaculator and needs therapy to learn to delay orgasm. So each culture defines the proper way to behave and to think about erotic stimulation. There are cultures where female breasts are not part of the erotic imagery, and there are cultures where obese or very thin individuals are thought to be sexually attractive. Some cultures stress only heterosexual preferences and others permit homosexual eroticism as well. So, it is clear that the specific ways in which we think, feel, and behave concerning erotic stimulation are socially learned.

Physical pleasure as a motivation for sexuality and as a consequence of sexual behaviour is often left unmentioned. The reason for this would seem to be that our culture has strived to restrict sexual behaviour and thus has tended to avoid mention of such pleasurable outcomes for fear of encouraging sexual behaviour. Nigeria cultural traditions have tended to stress negative consequences such as unwanted pregnancy, veneral disease, guilt, and social condemnation much more than any positive consequences of sexuality. Despite these social attitudes, it is clear that the pleasure component of sexuality is the major reinforcement for the learning of sexual attitudes and behaviours. Another common consequence of human sexual relationships is the development of psychological feelings of intimacy. Although sexual relationships without intimacy do occur, for example prostitution and casual sexual relationships (Oyefara, 2007a, 2007b). Sexual abstinence diminishes the risk of contracting sexually transmitted infections. On the other hand, it may necessitate relinquishing of potential health benefits of sex. For instance, empirical studies revealed that "men who reported the highest frequency of orgasm enjoyed a death rate half that of the laggards." Furthermore, the study shows that having sex even a few times a week may be associated with: improved sense of smell; reduced risk of heart disease; weight loss and overall fitness; reduced depression (in women); the relief or lessening of pain; less frequent colds and flu; better bladder control; better teeth; and improved prostate function. (Alexander, 2010). Despite these benefits of sex, risky sex with a lot of partners will probably do more harm than good most especially in the area of HIV/AIDS.

\section{HIV and sustainable human development in Nigeria}

Development is a multifaceted process often involving in addition to basic improvement in income and outputs, radical changes in institutional, social and administrative structures and in some instances, popular attitudes, customs and beliefs. In more simple way, human development can be seen as improvement in the quality of life of human beings in a country. 


\section{$\triangle$ Macrothink}

This involves constant availability of basic needs of human beings, such as adequate clothing, shelter, proper education, suitable food, regular supply of good water, adequate health care, regular supply of electricity, an effective communication system and other basic human needs. Sustainable human development on the other hand can be defined as that development that does not compromise the needs of future generation while simultaneously taking care of the present population (Oyefara, 2008). Central to sustainable development is the issue of health and HIV/AIDS. Available data reveal that HIV/AIDS factors have eroded most the gains Nigeria has made in the areas of health development. For example, HIV/AIDS has reduced the life expectancy by more than 6 years; it has increased the level of infant and maternal mortality. In addition, the health burden of the pandemic threatens the provision of other essential health cares for millions of Nigerians. Consequently, HIV/AIDS strongly militates against sustainable development of Nigeria.

\section{Conclusion}

Gender roles are learned and they can also be unlearned. Therefore, there is an urgent need to continue and sustain different programmes and activities on women's political and economic empowerment in Nigeria. This will invariably give women at both domestic and community level to be actively participating in all issues that affect their well-being, most especially their reproductive health. Federal Ministry of Women Affairs needs to collaborate with its counterparts at state level to improve the women self-esteem and their ability to negotiate for safe sex in the country. This will go a long way to reduce their susceptibility and vulnerability to HIV infection. Sustainable development is desirable and women as caregivers must be integrated as part of the process to achieve developmental goals in the country as stated in the NEEDS, MDGs and Federal Government 7 point agenda. Furthermore, there is a need strengthen the national HIV/AIDS response mechanisms, most especially at local government level to include improvement of women economic power, promotion of women's reproductive health rights and self esteem, prevention of mother to child transmission and total eradication of obnoxious cultural practices that made women to be at high risk of the virus. This invariably will contribute significantly to sustainable development in Nigeria.

\section{References}

Ainsworth, M and M. Over (1997), Confronting AIDS: Public Priorities in a Global Epidemic. World Bank Policy Research Report. Washington, D. C., Oxford University Press.

Alexander, B. (2010), Mounting evidence suggests sex helps keep us health. (http://www.msnbc.msn.com/id/5263250)

Daini, A. O. (2002), HIV/AIDS: Restoring Hope and Life, Lagos: Frankad.

Federal Ministry of Health (1999), HIV/ Syphilis Sentinel Sero-Prevalence survey in Nigeria: Technical Report: National AID/STDs control Programme November.

Federal Ministry of Health (2001), HIV/ Syphilis Sentinel Sero-Prevalence survey in Nigeria: Technical Report: National AID/STDs control Programme. November, Abuja. 
Federal Ministry of Health (2003), HIV/ Syphilis Sentinel Sero-Prevalence survey in Nigeria:

Technical Report: National AID/STDs control Programme, November

Federal Ministry of Health (2005), HIV/ Syphilis Sentinel Sero-Prevalence survey in Nigeria:

Technical Report: National AID/STDs control Programme, November

Federal Ministry of Health (2007) HIV/STI Integrated Biological and Behavioural Surveillance Survey (IBBSS, 2007) Federal Ministry of Health, Abuja, Nigeria

Federal Ministry of Health (2008), HIV/ Syphilis Sentinel Sero-Prevalence survey in Nigeria: Technical Report: National AID/STDs control Programme, November

Federal Ministry of Health (FMH) (2008b), National HIV/AIDS \& Reproductive Health Survey (NARHS), Federal Ministry of Health, Abuja, Nigeria.

Federal Ministry of Health and Social Services (1992): Bulletin of Epidemiology 9:10-16.

Federal Ministry of Health and Social Services (FMHSS) (1991), Sentinel Sero-prevalence Report, Abuja.

Federal Ministry of Health and Social Services (FMHSS) (1993), Sentinel Sero-prevalence Report, Abuja.

Federal Ministry of Health and Social Services (FMHSS) (1995), Sentinel Sero-prevalence Report, Abuja.

International Community of Women Living with HIV/AIDS (ICW) (1999), HIV/AIDS and HIV Transmission Fact Sheet, London, March.

Johnson, "Magic" E. (1992), Safer Sex: What you can do to avoid AIDS. New York: Arrow Books. Pp. 18-19.

Joint United Nations Programme On HIV/AIDS (UNAIDS) and World Health Organisation (WHO) (1998). AIDS Epidemic Update, December, Geneva.

Joint United Nations Programme on HIV/AIDS (UNAIDS) and World Health Organisation (WHO) (1999), AIDS Epidemic Update: May, Geneva, p.8.

Joint United Nations Programme on HIV/AIDS (UNAIDS) and World Health Organisation (WHO) (1998), AIDS Epidemic Update: May, Geneva, p.8.

Kiragu, K. (2001), "Youth and HIV/AIDS: Can We Avoid Catastrophe?” Population Reports Series L, No.12. Baltimore, The John Hopkins University Bloomberg School of Public Health, Population Information Program, p.3.

Laurence, J. (1999), "Women and AIDS" in AIDS Patient Care and STDS, 13 (2): 77-79, February.

National AIDS and STDs Control Programme/National Action Committee on AIDS/Futures Group International/United States Agency for International Development (2002), HIV/AIDS in Nigeria; Overview of the Epidemic. Federal Ministry of Health.

Oyefara, J.L (2007a), "An investigation of the variables influencing the use of condoms among prostitutes in Nigeria". The Nigerian Journal of Business and Social Sciences Volume 1, No. 1 Pp. 44-55.

Oyefara, J.L (2007b), "Food insecurity, HIV/AIDS pandemic and sexual behaviour of female commercial sex workers in Lagos metropolis, Nigeria”. SAHARA Journal of Social Aspect of HIV/AIDS Volume 4, No. 2, Pp. 626-635.

Oyefara, J.L. (2008), “Census Data, Socio-Economic Planning and Sustainable Development 
in Nigeria" in Oyekanmi, F.A.D and P.B. Ogunlade (eds.) Appraisal of the Preparation for 2006 Population and Housing Census in Nigeria. Lagos: Department of Sociology, University of Lagos. Pp. 33-46.

Ritzer, G. (2000): Modern Sociological Theory. Boston, McGraw Hill.

Royce, R.; and Sena, A.; Cates, W. and Cohen, M. (1997), "Sexual Transmission of HIV" in The New England Journal of Medicine, 336(15): 1072 - 1078. April. 10.

Tabifor, H. (2002), The Dignity of Human Sexuality and the AIDS challenge. Kenya: Alpha and Omega.

Watstein, S. and Laurich, R. (1991), AIDS and Women: A Source Book. Phoenix, Arizona, Oryx Press, p. 159.

\begin{abstract}
About the Author:
Dr. John Lekan Oyefara has a B.Sc in Demography and Social Statistics from Obafemi Awolowo University, Ile-Ife, Nigeria. In addition, he obtained a M.Sc and $\mathrm{PhD}$ in Sociology from the University of Ibadan, Nigeria. He specializes in Demography and Population Studies. His areas of research include fertility, mortality, migration, nuptiality, family planning, gender studies, public and reproductive health including HIV/AIDS. He has worked for over fifteen years in the development sector with local and international organizations in Nigeria. He is currently a senior lecturer in the Department of Sociology, Faculty of Social Sciences, University of Lagos, Nigeria.
\end{abstract}

